\title{
A New Energetic Complex: Synthesis, Structure, and Combustion Catalysis Performance
}

\author{
Chengfang Qiao, ${ }^{\circ a}$ Zhengyu Fu, ${ }^{a}$ Runrun Wang, ${ }^{a}$ Yulin Gao, ${ }^{a}$ Fengying Chen, ${ }^{a}$ \\ Xia Gao, ${ }^{a}$ Chunsheng Zhou ${ }^{*, a}$ and Zhengqiang Xia ${ }^{\circledR} * b$
}

${ }^{a}$ Shaanxi Key Laboratory of Comprehensive Utilization of Tailings Resources, College of Chemical Engineering and Modern Materials, Shangluo University, 726000 Shangluo, PR China

${ }^{b}$ Key Laboratory of Synthetic and Natural Functional Molecule Chemistry of Ministry of Education, College of Chemistry and Materials Science, Northwest University, Xi'an 710127, PR China

\begin{abstract}
The potential of tetrazole-based ligands for forming energetic complexes applied in pyrotechnics and propellants is demonstrated with the use of 5,5'-(1,3-phenylene)bis( $1 H$-tetrazole $)\left(\mathrm{H}_{2} \mathrm{BTB}\right)$ to generate an energetic complex with high energy. A new energetic complex of $\mathrm{Pb}^{\mathrm{II}}$-tetrazolate, $\left[\mathrm{Pb}_{2}(\mathrm{BTB})_{2}\left(\mathrm{H}_{2} \mathrm{O}\right)_{8}\right] \cdot 5 \mathrm{H}_{2} \mathrm{O}(\mathbf{1})$, was synthesized and structurally characterized by single crystal $\mathrm{X}$-ray diffraction. Structural analysis reveals that the central $\mathrm{Pb}^{\mathrm{II}}$ ions present two distinct coordination environments in the asymmetric unit, including distorted pentagonal bipyramid and distorted tetragonal pyramid geometries, respectively. To identify potential combustion catalyst as additives in propellants, we employed differential scanning calorimetry technique to evaluate the influence of the complex on thermal decomposition of ammonium perchlorate (AP) and cyclotrimethylenetrinitramine (RDX). The kinetic parameters of an exothermic process for the catalytic system of RDX+1 were investigated by the Kissinger's and Ozawa-Doyle's methods. For both AP and RDX, the decomposition temperature decreased obviously in the presence of $\mathbf{1}$, and the released heat could effectively compensate the propellants. Our observations demonstrate that $\mathbf{1}$ shows good catalytic activity toward the thermal decomposition of AP and RDX.
\end{abstract}

Keywords: tetrazole-based complex, non-isothermal kinetics, ammonium perchlorate, combustion catalysis

\section{Introduction}

The design and preparation of energetic materials that combine high performance and low sensitivity have been widely studied for military and civilian applications over the last decades. ${ }^{1,2}$ Nitrogen-rich heterocycles, featuring high nitrogen content and heats of formation, can generally derive energy from ring or cage strain and the oxidation of their carbon backbone to mainly yield environmentally friendly $\mathrm{N}_{2}$ molecules as end-product of propulsion or explosion..$^{3-6}$ Given the generation of gasses, these derivatives show potential applications as promising materials in explosives, solid propellants, and other thermal decomposition and combustible systems. ${ }^{7-10}$ 5,5'-(1,3-Phenylene)bis( $1 H$-tetrazole) $\left(\mathrm{H}_{2} \mathrm{BTB}\right)$, not only exhibits a high nitrogen content of $52.3 \%$ but also contains

*e-mail: slzhoucs@126.com; northwindy@126.com rich electron pairs, which can react with some Lewis acids to generate stable salts or coordinate with metal ions to form energetic complexes. ${ }^{11,12}$ Herein, a new energetic complex, $\left[\mathrm{Pb}_{2}(\mathrm{BTB})_{2}\left(\mathrm{H}_{2} \mathrm{O}\right)_{8}\right] \cdot 5 \mathrm{H}_{2} \mathrm{O}(\mathbf{1})$, is prepared by a hydrothermal approach, serving as solid combustion catalyst in the thermal decomposition of cyclotrimethylenetrinitramine (RDX) and ammonium perchlorate (AP). At the same time, either AP or RDX is the representative ingredient of powerful explosives or solid propellants and commonly used as oxidizer in rocket propellants. ${ }^{13,14} \mathrm{We}$ anticipate that the $\mathrm{Pb}^{\mathrm{II}}$-based complex $\mathbf{1}$ as additive and catalyst would not only provide active ingredient $\mathrm{Pb}$ or $\mathrm{PbO}$ at the molecular level, ${ }^{15-17}$ but also endow the catalyst system with greater heat of formation. As a result, the catalytic performances of $\mathbf{1}$ on the thermal decomposition of AP and RDX are investigated, which show that $\mathbf{1}$ can reduce the exothermic decomposition temperature and improve decomposition efficiency of AP/RDX at lower burning temperature. 


\section{Experimental}

Caution

$\mathrm{H}_{2} \mathrm{BTB}$ in its dehydrated form shows increasing friction and impacts sensitivity; $\mathrm{Pb}^{\mathrm{II}}$-based $\mathrm{H}_{2} \mathrm{BTB}$ complex is energetic material. Appropriate safety precautions should be taken.

\section{Materials and methods}

All reagents were purchased commercially and used without further purification. Lead nitrate, ammonia (10\%, $\mathrm{m} / \mathrm{m}$ ), ammonium perchlorate were purchased from SigmaAldrich (Xi'an, China). Cyclotrimethylenetrinitramine was obtained from Xi'an Modern Chemistry Research Institute (Xi' an, China). $\mathrm{H}_{2}$ BTB was synthesized according to literature. ${ }^{18}$ Elemental analyses were carried out with an Elementar Vario EL III analyzer. Infrared (IR) spectra were recorded with pressed $\mathrm{KBr}$ pellets on a Tensor 27 spectrometer (Bruker Optics, Ettlingen, Germany). Potassium bromide ( $>99.5 \%, \mathrm{~m} / \mathrm{m}$ ) was purchased from Sigma-Aldrich (Xi'an, China). Thermogravimetric (TG) measurements were performed on a Netzsch STA449C apparatus under a nitrogen atmosphere with a heating rate of $10{ }^{\circ} \mathrm{C} \mathrm{min}{ }^{-1}$ from 30 to $800{ }^{\circ} \mathrm{C}$. Differential scanning calorimetry (DSC) tests were measured with a thermal analyzer of PerkinElmer Pyris 6 DSC (calibrated by standard pure indium and zinc). X-ray diffraction (XRD) patterns were measured on a Rigaku D/max-IIIA X-ray diffractometer with graphite monochromatized $\mathrm{Cu} \mathrm{K \alpha}$ $(\lambda=1.54056 \AA)$.

Synthesis of $\left[\mathrm{Pb}_{2}(\mathrm{BTB})_{2}\left(\mathrm{H}_{2} \mathrm{O}\right)_{8}\right] \cdot 5 \mathrm{H}_{2} \mathrm{O}(1)$

A mixture of $\mathrm{Pb}\left(\mathrm{NO}_{3}\right)_{2}(0.1936 \mathrm{~g}, 0.5 \mathrm{mmol}), \mathrm{H}_{2} \mathrm{BTB}$ $(0.1071 \mathrm{~g}, 0.5 \mathrm{mmol}), \mathrm{NH}_{3} \cdot \mathrm{H}_{2} \mathrm{O}(10 \%, 0.2 \mathrm{~mL})$ was suspended in $5 \mathrm{~mL} \mathrm{H}_{2} \mathrm{O}$, and heated in a 10 -mL Teflon-lined stainless reactor at $130{ }^{\circ} \mathrm{C}$ for three days. After cooling to room temperature at a rate of $10{ }^{\circ} \mathrm{C} \mathrm{h}^{-1}$, colorless crystals were collected, washed with water and dried in air. Yield: $61 \%$ (based on $\mathrm{Pb}^{2+}$ ); IR (KBr) v / cm ${ }^{-1} 3511,3454,1635$, 1450, 1364, 1270, 1207, 1151, 1119, 1107, 1029, 1007, 860, 751, 737, 688, 597. Anal. calcd. for $\mathrm{C}_{16} \mathrm{H}_{34} \mathrm{~N}_{16} \mathrm{O}_{13} \mathrm{~Pb}_{2}$ (relative molecular mass $\left.\left(\mathrm{M}_{\mathrm{r}}\right)=1072.97\right)$ : C 17.91, N 20.89, H 3.19; found: C 18.05, N 20.78, H 3.22.

\section{X-ray crystal structure determination}

The collection of single crystal X-ray data of $\mathbf{1}$ was performed on a Bruker Smart Apex CCD diffractometer equipped with graphite monochromatized Mo $\mathrm{K} \alpha$ radiation ( $\lambda=0.71073 \AA)$ using $\omega$ and $\varphi$ scan modes. The crystal structure of complex was solved by direct methods and refined with full-matrix least-squares refinements based on $\mathrm{F}^{2}$ using SHELXTL ${ }^{19}$ and SHELXL-9720 programs. All non-hydrogen atoms were refined anisotropically. Hydrogen atoms of the ligands were placed in geometrically calculated positions. Crystallographic data are summarized in Table 1, selected bond lengths are shown in Table 2, and hydrogen bonding interactions are shown in Table 3.

Table 1. Crystal data and structure refinement summary for $\mathbf{1}$

\begin{tabular}{|c|c|}
\hline Empirical formula & $\mathrm{C}_{16} \mathrm{H}_{34} \mathrm{~N}_{16} \mathrm{O}_{13} \mathrm{~Pb}_{2}$ \\
\hline Formula weight & 1072.97 \\
\hline Crystal system & monoclinic \\
\hline Space group & $P 21 / c$ \\
\hline$a / \AA$ & $13.516(3)$ \\
\hline$b / \AA$ & $9.901(2)$ \\
\hline$c / \AA$ & $25.699(4)$ \\
\hline$\alpha /$ degree & 90 \\
\hline$\beta /$ degree & $110.138(9)$ \\
\hline$\gamma /$ degree & 90 \\
\hline $\mathrm{V} / \AA^{3}$ & $3228.8(11)$ \\
\hline $\mathrm{Z}$ & 4 \\
\hline$\rho_{\text {calc }} /\left(\mathrm{g} \mathrm{cm}^{-3}\right)$ & 2.207 \\
\hline$\mu / \mathrm{mm}^{-1}$ & 10.498 \\
\hline $\mathrm{F}(000)$ & 2040 \\
\hline Reflections collected/unique & $15318 / 5698$ \\
\hline R(int) & 0.0650 \\
\hline Data/restraints/parameters & $5698 / 216 / 424$ \\
\hline Goodness-of-fit on $\mathrm{F}^{2}$ & 3.220 \\
\hline Final $R$ indices $[I>2 \sigma(I)]$ & $\mathrm{R}_{1}=0.1106, \mathrm{wR}_{2}=0.2127$ \\
\hline $\mathrm{R}$ indices (all data) & $\mathrm{R}_{1}=0.1452, \mathrm{wR}_{2}=0.2181$ \\
\hline Largest diff. peak and hole / $\left(\mathrm{e} \mathrm{nm}^{-3}\right)$ & 11692 and -4166 \\
\hline
\end{tabular}

$\mathrm{V}$ : volume; $\rho_{\text {calc }}$ : calculated density; $\mu$ : absorption coefficient; $F(000)$ : structure factor in the zeroth-order case; $\mathrm{F}^{2}$ : squared structure factor; $w R^{2}$ : R-value for $\mathrm{F}^{2}$.

Table 2. Selected bond lengths in $\mathbf{1}$

\begin{tabular}{lc}
\hline \multicolumn{3}{c}{ Bond length / } \\
\hline $\mathrm{Pb}(1)-\mathrm{O}(4)$ & $2.471(12)$ \\
$\mathrm{Pb}(1)-\mathrm{O}(5)$ & $2.535(13)$ \\
$\mathrm{Pb}(1)-\mathrm{O}(6)$ & $2.385(15)$ \\
$\mathrm{Pb}(1)-\mathrm{O}(7)$ & $2.763(6)$ \\
$\mathrm{Pb}(1)-\mathrm{O}(8)$ & $2.801(4)$ \\
$\mathrm{Pb}(1)-\mathrm{N}(10)$ & $2.704(18)$ \\
$\mathrm{Pb}(2)-\mathrm{O}(1)$ & $2.631(13)$ \\
$\mathrm{Pb}(2)-\mathrm{O}(2)$ & $2.437(16)$ \\
$\mathrm{Pb}(2)-\mathrm{O}(3)$ & $2.593(14)$ \\
$\mathrm{Pb}(2)-\mathrm{N}(2)$ & $2.63(2)$ \\
\hline
\end{tabular}


Table 3. Hydrogen bonding interactions in $\mathbf{1}$

\begin{tabular}{|c|c|c|c|c|}
\hline $\mathrm{D}-\mathrm{H} \cdots \mathrm{A}$ & $\mathrm{D}-\mathrm{H} / \AA$ & $\mathrm{H} \cdots \mathrm{A} / \AA$ & $\mathrm{D} \cdots \mathrm{A} / \AA$ & $<$ DHA / degree \\
\hline $\mathrm{O}(13)-\mathrm{H}(13 \mathrm{~B}) \cdots \mathrm{N}(15) \# 1$ & 0.83 & 2.68 & $3.41(3)$ & 147.0 \\
\hline $\mathrm{O}(13)-\mathrm{H}(13 \mathrm{~B}) \cdots \mathrm{N}(14) \# 1$ & 0.83 & 1.94 & $2.76(2)$ & 176.2 \\
\hline $\mathrm{O}(12)-\mathrm{H}(12 \mathrm{~B}) \cdots \mathrm{O}(11) \# 2$ & 0.85 & 1.89 & $2.69(2)$ & 156.4 \\
\hline $\mathrm{O}(1)-\mathrm{H}(1 \mathrm{~B}) \cdots \mathrm{N}(7) \# 3$ & 0.85 & 2.08 & $2.88(3)$ & 156.9 \\
\hline $\mathrm{O}(2)-\mathrm{H}(2 \mathrm{~A}) \cdots \mathrm{O}(3)$ & 0.85 & 2.45 & $3.23(2)$ & 151.9 \\
\hline $\mathrm{O}(7)-\mathrm{H}(7 \mathrm{~B}) \cdots \mathrm{N}(11) \# 4$ & 0.85 & 2.70 & $3.55(3)$ & 176.8 \\
\hline $\mathrm{O}(12)-\mathrm{H}(12 \mathrm{~A}) \cdots \mathrm{N}(5)$ & 0.85 & 1.98 & $2.73(2)$ & 146.2 \\
\hline $\mathrm{O}(8)-\mathrm{H}(8 \mathrm{~B}) \cdots \mathrm{O}(3) \# 5$ & 0.85 & 2.51 & $3.30(2)$ & 154.9 \\
\hline $\mathrm{O}(12)-\mathrm{H}(12 \mathrm{~A}) \cdots \mathrm{N}(6)$ & 0.85 & 2.70 & $3.43(2)$ & 146.2 \\
\hline $\mathrm{O}(6)-\mathrm{H}(6 \mathrm{~A}) \cdots \mathrm{O}(12) \# 6$ & 0.85 & 1.85 & $2.70(2)$ & 174.9 \\
\hline $\mathrm{O}(1)-\mathrm{H}(1 \mathrm{~A}) \cdots \mathrm{N}(13) \# 7$ & 0.85 & 1.94 & $2.73(2)$ & 154.7 \\
\hline
\end{tabular}

D: donor of hydrogen bonds; $\mathrm{H}$ : hydrogen atom; A: acceptor of hydrogen bonds; \#1: $-\mathrm{x}+1,-\mathrm{y},-\mathrm{z}+2$; \#2: $\mathrm{x},-\mathrm{y}+3 / 2, \mathrm{z}-1 / 2 ; \# 3:-\mathrm{x},-\mathrm{y}+1,-\mathrm{z}+1$; $\# 4:-x+1, y+1 / 2,-z+3 / 2 ; \# 5: x,-y+1 / 2, z+1 / 2 ; \# 6: x, y-1, z ; \# 7: x-1, y, z-1$.

\section{Results and Discussion}

Crystal structure of $\left[\mathrm{Pb}_{2}(\mathrm{BTB})_{2}\left(\mathrm{H}_{2} \mathrm{O}\right)_{8}\right] \cdot 5 \mathrm{H}_{2} \mathrm{O}(\mathbf{1})$

Compound 1 crystallizes in the monoclinic crystal system with $P 21 / \mathrm{n}$ space group, and the two different coordination environments of $\mathrm{Pb}^{2+}$ ions in $\mathbf{1}$ are depicted in Figure 1a. Single-crystal X-ray analysis reveals that it contains two unique $\mathrm{Pb}^{2+}(\mathrm{Pb} 1$ and $\mathrm{Pb} 2)$, two fully deprotonated $\mathrm{BTB}^{2-}$ anions, eight coordinated water molecules and five lattice water molecules in the asymmetric unit. The $\mathrm{Pb} 1$ ion is six-coordinated by a nitrogen atom from one $\mathrm{BTB}^{2-}$ ligand and five water molecules, whereas $\mathrm{Pb} 2$ is four-coordinated by one nitrogen atom from one tetrazolate ring and three water molecules. The coordination geometries around $\mathrm{Pb} 1$ and $\mathrm{Pb} 2$ can be described as $\psi-\mathrm{PbNO}_{5}$ distorted
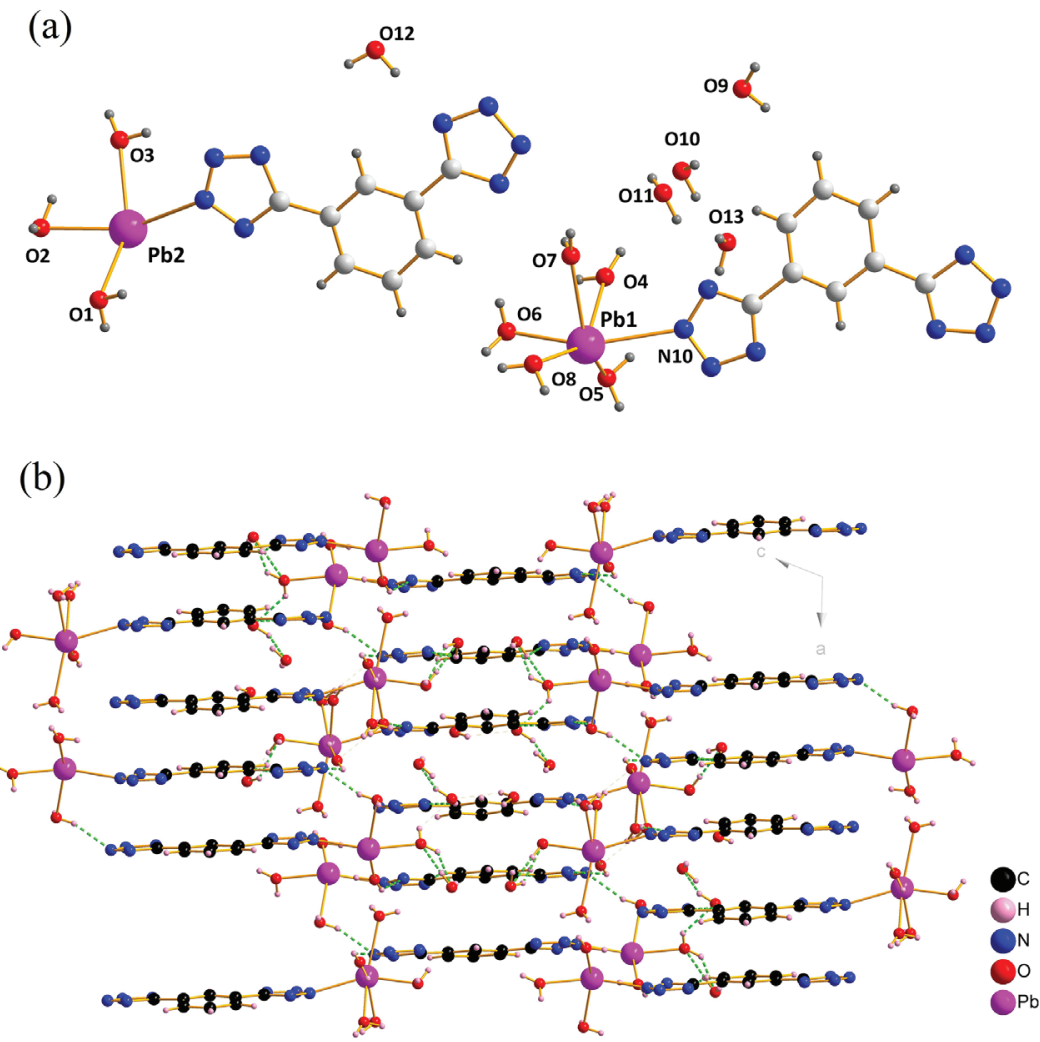

Figure 1. (a) Asymmetric unit of 1; (b) 3D hydrogen bond framework of 1 viewed along the $b$-axis. 
pentagonal bipyramid and $\psi-\mathrm{PbNO}_{3}$ distorted tetragonal pyramid, respectively. The average $\mathrm{Pb}(1)-\mathrm{N}$ distance is 2.704(18) $\AA$, and $\mathrm{Pb}(1)-\mathrm{O}$ distances range from 2.385(15) to 2.801(4) $\AA$ (Table 2). These distances are comparable to those reported in other lead(II) complexes..$^{21}$ For $\mathrm{Pb} 2$ center, the basal vertices is formed by atoms $\mathrm{N}(2), \mathrm{O}(1), \mathrm{O}(2)$ and $\mathrm{O}(3)$, with the bond lengths of $\mathrm{Pb}(2)-\mathrm{O}(1)=2.631(13) \AA$, $\mathrm{Pb}(2)-\mathrm{O}(2)=2.437(16) \AA, \mathrm{Pb}(2)-\mathrm{O}(3)=2.593(14) \AA$ and $\mathrm{Pb}(2)-\mathrm{N}(2)=2.63(2) \AA$.

Thirteen water molecules (eight ligated and five lattices) are included in the asymmetric unit, therefore a variety of $\mathrm{O}-\mathrm{H} \cdots \mathrm{O}$ and $\mathrm{O}-\mathrm{H} \cdots \mathrm{N}$ H-bonding interactions can be found in the structure of $\mathbf{1}$. Oxygen atoms can act as hydrogen-bond donors and acceptors from water molecules, which extensively participate in stabilizing the network by $\mathrm{H}$-bond interactions, as depicted in Figure 1b. Especially, the $\mathrm{O}$-bond $\mathrm{H}$ atom in lattice water molecule is located on the $\mathrm{O} 12$ atom, and interacts with the free water molecule

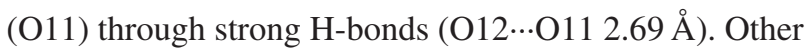
interatomic distances between the hydrogen-bond donor and acceptor range from 2.70 to $3.55 \AA$. Three-dimensional supramolecular framework are further constructed through $\mathrm{H}$-bonds along the $b$-axis (Figure 1b).

It should be noted that abundant and strong intermolecular $\pi-\pi$ stacking interactions are observed between the aromatic rings in 1. As displayed in Figure 2, the aromatic planes from different $\mathrm{BTB}^{2-}$ ligands are parallel to each other. The tetrazole ring $\mathrm{C} 9-\mathrm{N} 9-\mathrm{N} 10-\mathrm{N} 11-\mathrm{N} 12$ stacks with other two different tetrazole rings C16-N13-N16-N15-N14 and $\mathrm{C} 8-\mathrm{N} 5-\mathrm{N} 6-\mathrm{N} 7-\mathrm{N} 8$ to form strong off-set face-toface $\pi-\pi$ interactions with centroid-to-centroid distances of 3.50-3.61 $\AA(\mathrm{Cg} \cdots \mathrm{Cg}<3.7 \AA)$, while relatively weak face-to-face $\pi-\pi$ interactions are found between the benzene rings with centroid-to-centroid separation of $3.889 \AA$. Obviously, these supramolecular interactions benefit the stability of the energetic complex.

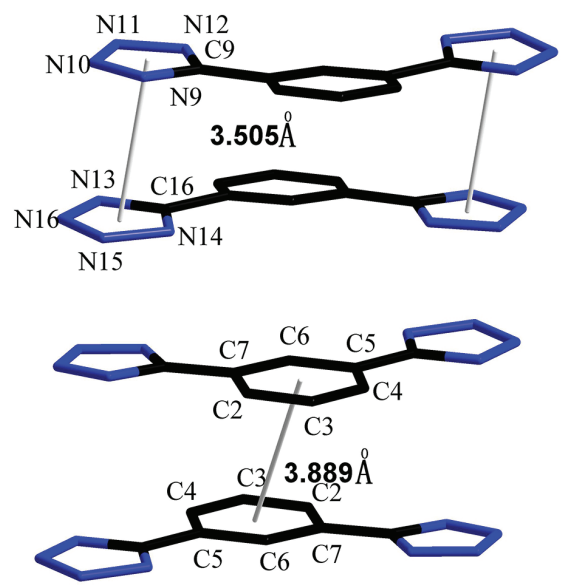

Thermal gravimetric analysis and XRD

As shown in Figure 3a for 1, TG-DSC measurements were carried out between 30 and $800{ }^{\circ} \mathrm{C}$. In the TG curve of $\mathbf{1}$, a continuous weight loss of $21.25 \%$ in the range of $50-160{ }^{\circ} \mathrm{C}$ may ascribe to the departure of five lattice water molecules and eight coordinated water molecules (calcd. $21.82 \%)$. Notably, the dehydrating process occurs below $200{ }^{\circ} \mathrm{C}$, implying that the dehydrated $\mathbf{1}$ can be considered as combustion catalyst with low signature. The residual keeps stable up to $275^{\circ} \mathrm{C}$ and then undergoes two steps of decomposition, which ends until about $500{ }^{\circ} \mathrm{C}$. The first decomposition step of compound $\mathbf{1}$ starts at $275{ }^{\circ} \mathrm{C}$ and ends at $360{ }^{\circ} \mathrm{C}$, during which the structure collapses and the energetic $\mathrm{H}_{2} \mathrm{BTB}$ ligands decompose, corresponding to a rapid and sharp heat release ranging from 285 to $305^{\circ} \mathrm{C}$ on DSC curve. The peak temperature of decomposition is $298.6^{\circ} \mathrm{C}$. Whereas, the second one occurring in the range of $404-500{ }^{\circ} \mathrm{C}$ gives a broad exothermal peak centered at $523.4{ }^{\circ} \mathrm{C}$. As depicted in Figure 3b, X-ray powder diffraction experiment has been carried out to confirm the phase purity of the as-synthesized powder sample of the complex 1. The experimental pattern matches well with the corresponding simulated one, suggesting the good phase purity of the as-synthesized product.

Influence on the thermal decomposition of AP and RDX

The catalytic effect of the energetic complex 1 on the thermal decomposition of AP was evaluated by DSC testing (Figure 4). For pure AP, the endothermic peak at $245^{\circ} \mathrm{C}$ is ascribed to the phase transformation. The exothermic peaks at 290 and $442{ }^{\circ} \mathrm{C}$ correspond to the low-temperature decomposition (LTD) and high-temperature decomposition (HTD) processes with the heat releases of 735 and $787 \mathrm{~J} \mathrm{~g}^{-1}$, respectively. ${ }^{22,23}$ The DSC curves show that both the mixture

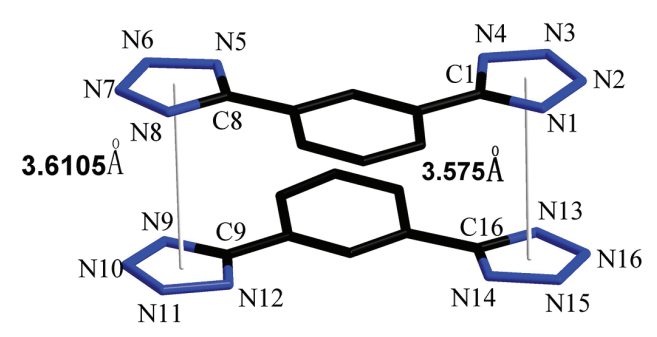

Figure 2. $\pi-\pi$ stacking interactions observed in $\mathbf{1}$ ( $\mathrm{H}$ atoms are omitted for clarity). 

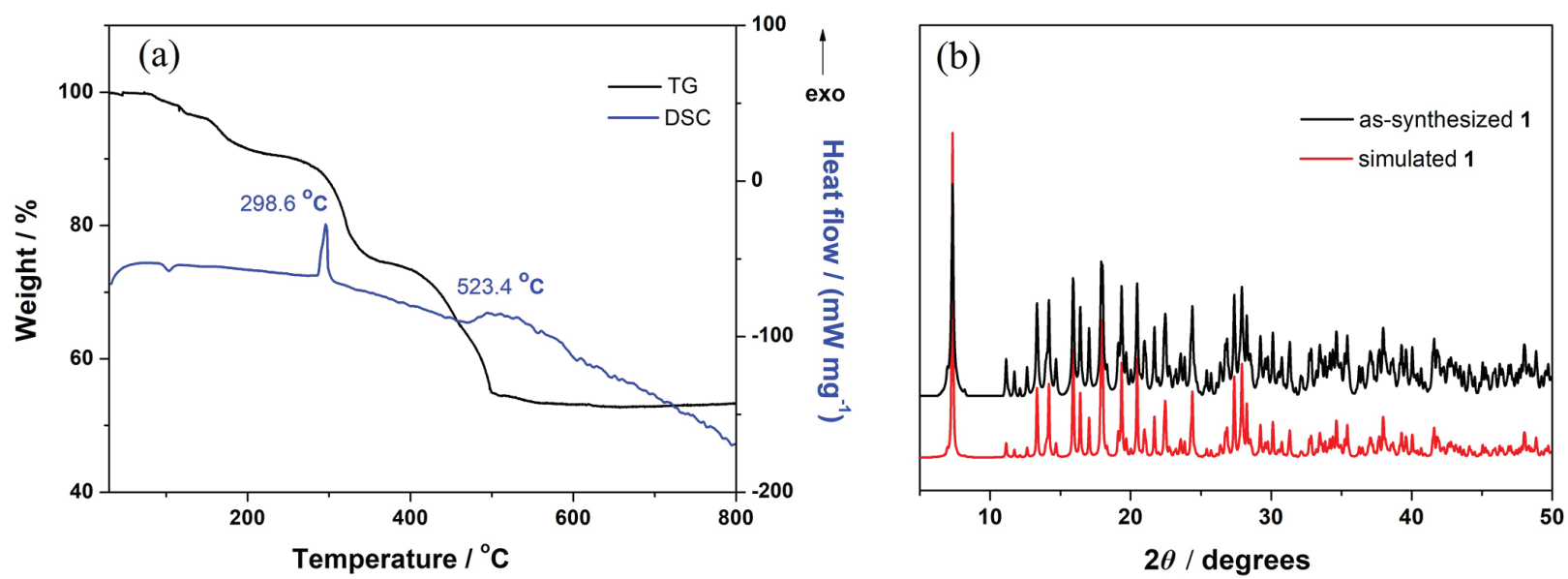

Figure 3. (a) TG-DSC curves of $\mathbf{1}$ at the heating rate of $10 \mathrm{~K} \mathrm{~min}^{-1}$; (b) powder XRD patterns of simulated and as-synthesized $\mathbf{1}$.

(a)

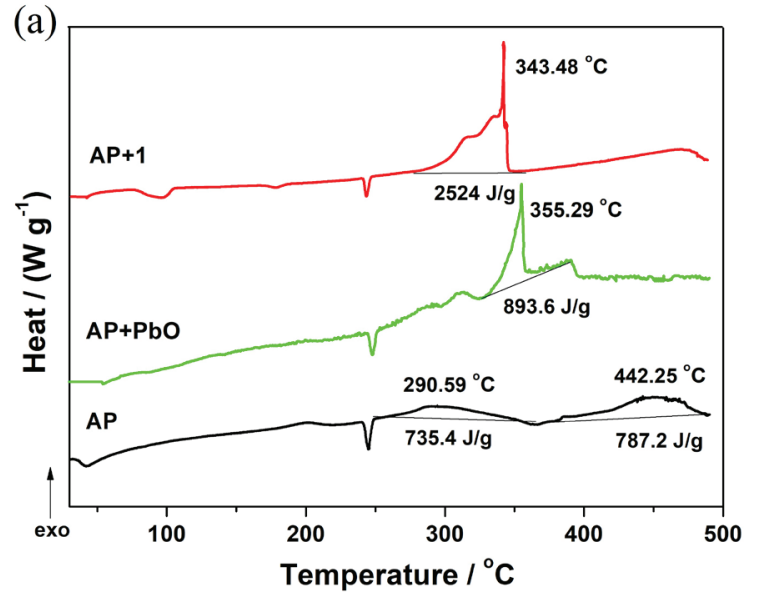

(b)

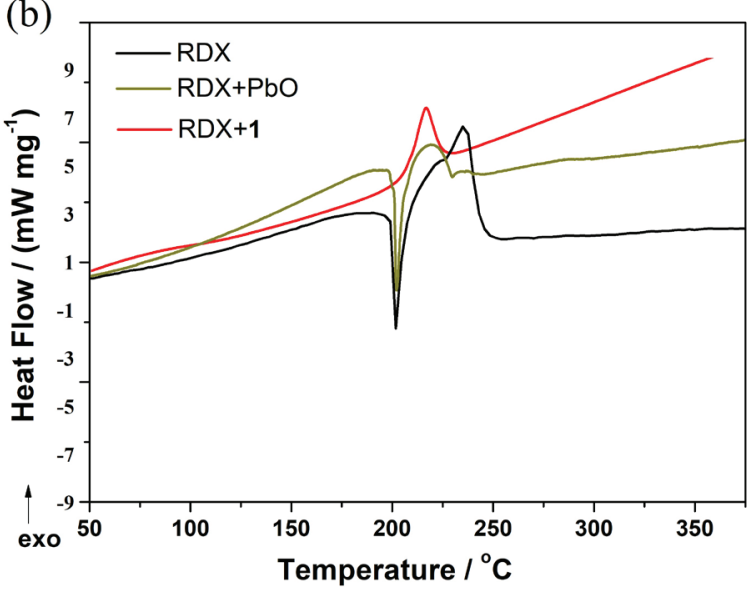

Figure 4. DSC curves of catalytic thermal decomposition of (a) AP and (b) RDX in the presence of $\mathbf{1}$ and $\mathrm{PbO}$ at a heating rate of $5 \mathrm{~K}_{\text {min }}{ }^{-1}$ under $\mathrm{N}_{2}$, wherein AP/RDX and catalyst are mixed at a mass ratio of 1:3 to prepare the target samples.

systems of $\mathrm{AP}+\mathbf{1}$ and $\mathrm{AP}+\mathrm{PbO}$ have no effects on the crystallographic transition, whereas the obvious changes can be seen in the decomposition phase. After the addition of catalyst, the two exothermic peaks of AP merge to one and the decomposition peak temperature reduces to 355 and $343{ }^{\circ} \mathrm{C}$ for the mixture systems of $\mathrm{AP}+\mathrm{PbO}$ and $\mathrm{AP}+\mathbf{1}$, respectively, indicating a fast decomposition process; the corresponding decomposition heat also changes to 893 and $2524 \mathrm{~J} \mathrm{~g}^{-1}$, respectively, dramatically higher than that of pure AP. In comparison with $\mathrm{PbO}$, the energetic complex 1 provides much more heat during the process of decomposition, endowing the catalyst system with more energy to promote the combustion rate of solid propellants. It is not difficult to find that large heat release and the following formation of metal and oxide at molecular level on propellant surface after the decomposition of the energetic complex may contribute to the outstanding catalytic effects..$^{24,25}$

Furthermore, the catalytic effect of the complex 1 on RDX was also investigated by DSC experiments at a heating rate of $5 \mathrm{~K} \mathrm{~min}^{-1}$ with $\mathrm{Al}_{2} \mathrm{O}_{3}$ as reference. As shown in Figure 4b, a sharp endothermic peak at about $203{ }^{\circ} \mathrm{C}$ is observed in the curves of pure RDX or $\mathrm{RDX}+\mathrm{PbO}$, which can be attributed to the sublimation and melting processes of RDX. Meanwhile, a broad exothermal peak centered at $234.5^{\circ} \mathrm{C}$ is found in the absence of any catalyst. After mixing $\mathbf{1}$ or $\mathrm{PbO}$ with RDX, the exothermic peak temperature can be shifted from 234.5 to 218.6 and $219.8^{\circ} \mathrm{C}$, respectively, extremely lower than that of pure RDX. Notably, the endothermic peak in the presence of $\mathbf{1}$ nearly disappears because of the heat compensation in the thermal-decomposition process. Similar to AP, the complex 1 shows distinct energetic performance on the RDX. The great average bond energies of $\mathrm{C}-\mathrm{N}\left(273 \mathrm{~kJ} \mathrm{~mol}^{-1}\right), \mathrm{N}-\mathrm{N}\left(160 \mathrm{~kJ} \mathrm{~mol}^{-1}\right)$ and $\mathrm{N}=\mathrm{N}$ $\left(418 \mathrm{~kJ} \mathrm{~mol}^{-1}\right.$ ) of the energetic ligand $\mathrm{H}_{2} \mathrm{BTB}$ provide larger heat of formation, resulting in an increase of heat release and further enhancement of the catalytic efficiency for AP and RDX. ${ }^{26-28}$ In addition, the active component of $\mathrm{Pb}$ in the complex can be converted into $\mathrm{PbO}$ or $\mathrm{PbN}_{3}$, 
which subsequently provides a lot of heat to accelerate the thermal-decomposition of RDX and decrease the thermaldecomposition temperature. ${ }^{17,21}$

The apparent activation energy $\left(E_{a}\right)$ and the preexponential factor (A) are two crucial factors to study the thermokinetics of the decomposition processes of RDX, which were calculated by Kissinger's method ${ }^{29}$ and Ozawa's method. ${ }^{30,31}$ The exothermic peak temperatures were demonstrated based on the four DSC curves with the heating rates of $2,5,8$, and $10 \mathrm{~K} \mathrm{~min}^{-1}$. The apparent activation energies $\mathrm{E}_{\mathrm{aK}}$ (obtained by Kissinger method) and $\mathrm{E}_{\mathrm{aO}}$ (obtained by Ozawa method), pre-exponential factor $\mathrm{A}$ and linear correlation coefficients $\mathrm{R}_{\mathrm{K}}$ (based on Kissinger method) and $R_{\mathrm{O}}$ (based on Ozawa method) are listed in Table 4. The Kissinger (equation 1) and Ozawa-Doyle (equation 2) equations are as follows:

$\ln \left(\frac{\beta}{T_{p}^{2}}\right)=\ln \frac{A R}{E_{a K}}-\frac{E_{a K}}{R} \frac{1}{T_{p}}$

$\log \beta+\frac{0.4567 \mathrm{E}_{\mathrm{aO}}}{\mathrm{RT}_{\mathrm{p}}}=\mathrm{C}$

where $T_{p}$ is the peak temperature; $R$ is the gas constant, $8.314 \mathrm{~J} \mathrm{~mol}^{-1} \mathrm{~K}^{-1} ; \beta$ is the linear heating rate; and $\mathrm{C}$ is a constant. By the above calculations, the calculated value of $E_{a}$ (the average of $E_{a K}$ and $E_{a 0}$ ) of the mixture system of $\mathrm{RDX}+\mathbf{1}$ is $97.78 \mathrm{~kJ} \mathrm{~mol}^{-1}$. Compared with the pure RDX, ${ }^{32}$ the apparent activation energy of the system decreases by

Table 4. Thermokinetic parameters of the exothermic processes of the mixture system of RDX $+\mathbf{1}$ at different heating rates

\begin{tabular}{lc}
\hline Heating rate $/\left(\mathrm{K} \mathrm{min}^{-1}\right)$ & Peak temperature $/{ }^{\circ} \mathrm{C}$ \\
\hline 2 & 205.1 \\
5 & 218.6 \\
8 & 230.1 \\
10 & 236.2 \\
\hline Kissinger method $\left(\mathrm{E}_{\mathrm{aK}}\right) /\left(\mathrm{kJ} \mathrm{mol}^{-1}\right)$ & 96.24 \\
ln A & 17.889 \\
$\mathrm{R}_{\mathrm{K}}$ & 0.9903 \\
Ozawa method $\left(\mathrm{E}_{\mathrm{aO}}\right) /\left(\mathrm{kJ} \mathrm{mol}^{-1}\right)$ & 99.32 \\
$\mathrm{R}_{\mathrm{O}}$ & 0.9918 \\
$\mathrm{E}_{\mathrm{a}} /\left(\mathrm{kJ} \mathrm{mol}^{-1}\right)$ & 97.78 \\
$\mathrm{E}_{\mathrm{a}} /\left(\mathrm{kJ} \mathrm{mol}^{-1}\right)$ of $\mathrm{RDX}^{\mathrm{a}}$ & 136.78 \\
\hline
\end{tabular}

abtained from the publication of Cui et al. ${ }^{32} \mathrm{E}_{\mathrm{aK}}$ : apparent activation energy obtained by Kissinger method; ${ }^{29} \mathrm{~A}$ : pre-exponential factor; $\mathrm{R}_{\mathrm{K}}$ : linear correlation coefficient based on Kissinger method; ${ }^{29}$ $\mathrm{E}_{\mathrm{a}}$ : apparent activation energy obtained by Ozawa method; ${ }^{30} \mathrm{R}_{\mathrm{O}}$ : linear correlation coefficient based on Ozawa method; ${ }^{30} \mathrm{E}_{\mathrm{a}}$ : apparent activation energy; RDX: cyclotrimethylenetrinitramine.
$39 \mathrm{~kJ} \mathrm{~mol}^{-1}$. Accordingly, the ln A for the system (17.889) is higher than that of the pure RDX ( $\ln \mathrm{A}=13.68),{ }^{32}$ which implies a faster thermal decomposition rate. Based on the above calculated results, the Arrhenius equations can be expressed as follows: $\ln \mathrm{k}=17.889-97.78 \times 10^{3} /(\mathrm{RT})$ for the exothermic process, where $\mathrm{k}$ is the thermal decomposition rate constant, which can be used to estimate the rate constant of the initial thermal decomposition process of the mixture system of RDX $+\mathbf{1}$ and predict the thermal decomposition mechanisms.

\section{Conclusions}

In summary, a new $\mathrm{Pb}^{\mathrm{II}}$-based energetic complex $\left[\mathrm{Pb}_{2}(\mathrm{BTB})_{2}\left(\mathrm{H}_{2} \mathrm{O}\right)_{8}\right] \cdot 5 \mathrm{H}_{2} \mathrm{O}$ (1) was constructed by $\mathrm{Pb}^{\mathrm{II}}$ ions and nitrogen-rich ligand 5,5'-(1,3-phenylene) bis $\left(1 H\right.$-tetrazole) $\left(\mathrm{H}_{2} \mathrm{BTB}\right)$. The $\mathrm{Pb} 1^{\mathrm{II}}$ ion locates in a $\psi-\mathrm{PbNO}_{5}$ distorted pentagonal bipyramid geometry, while the coordination configuration of $\mathrm{Pb} 2^{\mathrm{II}}$ can be described as a $\psi-\mathrm{PbNO}_{3}$ distorted tetragonal pyramid. DSC results showed that the $\mathbf{1}$ significantly accelerated the decomposition of AP with the decomposition temperature reducing from 442 to $343^{\circ} \mathrm{C}$ and the decomposition heat increasing from 1522 to $2524 \mathrm{~J} \mathrm{~g}^{-1}$, which was vastly superior to $\mathrm{PbO}$ catalyst. The outstanding catalytic activity of the energetic complex $\mathbf{1}$ can also be seen in the catalytic decomposition of RDX. Non-isothermal kinetics analysis reveals that the apparent activation energy of the mixture system of RDX $+\mathbf{1}$ is $97.78 \mathrm{~kJ} \mathrm{~mol}^{-1}$, which is obviously less than pure RDX by $39 \mathrm{~kJ} \mathrm{~mol}^{-1}$. The results above show that the complex would be exampled as high energy and excellent combustion catalyst in solid propellant field.

\section{Supplementary Information}

Checkcif report of the complex $\mathbf{1}$ is available free of charge at http://jbcs.sbq.org.br as a PDF file.

Crystallographic data (excluding structure factors) for the structure in this paper has been deposited in the Cambridge Crystallographic Data Centre as supplementary publication number CCDC 823763. Copies of the data can be obtained, free of charge, via www.ccdc.cam.ac.uk/conts/ retrieving.html or from the Cambridge Crystallographic Data Centre, CCDC, 12 Union Road, Cambridge CB2 1EZ, UK; fax: +441223 336033. E-mail: deposit@ccdc. cam.ac.uk.

\section{Acknowledgments}

We gratefully acknowledge financial support from the National Natural Science Foundation of China (Nos. 
21703135 and 21803042), the Natural Science Basic Research Program of Shaanxi (Nos. 2019JQ-249 and 2019JQ-067), the Natural Science Foundation of the Department of Education of Shaanxi Province (No. 17JS034) and the Innovative and Entrepreneurial Training Program for National College Students (No. 201811396012).

\section{Author Contributions}

Chengfang Qiao was responsible for the conceptualization, data curation, methodology, project administration, writing original draft, review and editing; Zhengyu Fu, Runrun Wang and Yulin Gao for the data curation; Zhengqiang Xia for the funding acquisition, project administration and writing review and editing; Chunsheng Zhou for the funding acquisition and resources; $\mathrm{Xia}$ Gao for the investigation; Fengying Chen for the software.

\section{References}

1. Ma, X.; Cai, C.; Sun, W.; Song, W.; Ma, Y.; Liu, X.; Xie, G.; Chen, S.; Gao, S.; ACS Appl. Mater. Interfaces 2019, 11, 9233.

2. Shang, Y.; Jin, B.; Peng, R.; Liu, Q.; Tan, B.; Guo, Z.; Zhao, J.; Zhang, Q.; Dalton Trans. 2016, 45, 13881.

3. Chi-Durán, I.; Enríquez, J.; Manquián, C.; Fritz, R. A.; Vega, A.; Serafini, D.; Herrera, F.; Singh, D. P.; ACS Omega 2019, 4, 14398.

4. Zhang, S.; Yang, Q.; Liu, X.; Qu, X.; Wei, Q.; Xie, G.; Chen, S.; Gao, S.; Coord. Chem. Rev. 2016, 307, 292.

5. McDonald, K. A.; Seth, S.; Matzger, A. J.; Cryst. Growth Des. 2015, 15, 5963.

6. Zhang, J.; Shreeve, J. M.; Dalton Trans. 2016, 45, 2363.

7. Wu, B.; Li, Y.; Li, F.; Zhou, Z.; Yang, L.; Zhang, J.; Zhang, T.; Polyhedron 2013, 55, 73.

8. Talawar, M.; Sivabalan, R.; Mukundan, T.; Muthurajan, H.; Sikder, A.; Gandhe, B.; Rao, A. S.; J. Hazard. Mater. 2009, $161,589$.

9. Qiao, C.; Lv, L.; Xu, W.; Xia, Z.; Zhou, C.; Chen, S.; Gao, S.; Acta Phys.-Chim. Sin. 2020, 36, 1905085.

10. Yang, Q.; Yang, G.; Zhang, W.; Zhang, S.; Yang, Z.; Xie, G.; Wei, Q.; Chen, S.; Gao, S.; Chem. - Eur. J. 2017, 23, 9149.
11. Fischer, D.; Klapötke, T. M.; Piercey, D. G.; Stierstorfer, J.; Chem. - Eur. J. 2013, 19, 4602.

12. Li, S.; Wang, Y.; Qi, C.; Zhao, X.; Zhang, J.; Zhang, S.; Pang, S.; Angew. Chem., Int. Ed. 2013, 52, 14031.

13. Chen, L.; Li, L.; Li, G.; J. Alloys Compd. 2008, 464, 532.

14. Tong, Y.; Liu, R.; Zhang, T.; Phys. Chem. Chem. Phys. 2014, $16,17648$.

15. Fu, X.; Fan, X.; Li, J.; Liu, X.; Zhang, L.; Chin. J. Explos. Propellants 2008, 31, 49.

16. Zhao, F.; Chen, P.; Luo, Y.; Zhang, R.; Li, S.; Chin. J. Explos. Propellants 2003, 26, 1 .

17. Wang, W.; Chen, S.; Gao, S.; Eur. J. Inorg. Chem. 2009, 3475.

18. Kelleher, F.; Mahon, M. F.; McGinley, J.; Prajapati, V.; Tetrahedron 2005, 61, 7002.

19. Sheldrick, G. M.; SHELXTL Reference Manual: Version 5.1; Bruker AXS Inc., Madison, WI, USA, 1997.

20. Sheldrick, G. M.; SHELXL-97: Program for Crystal Structure Refinement; University of Göttingen, Germany, 1997.

21. Li, Y. P.; Krivovichev, S. V.; Burns, P. C.; J. Solid State Chem. 2000, 153, 365.

22. Lang, S. V.; Combust. Flame 2006, 145, 779.

23. Vyazovkin, S.; Wight, C. A.; Chem. Mater. 1999, 11, 3386.

24. Kulkarni, P. B.; Reddy, T. S.; Nair, J. K.; Nazare, A. N.; Talawar, M. B.; Mukundan, T.; Asthana, S. N.; J. Hazard. Mater. 2005, $123,54$.

25. Li, B.; Shen, D.; Chen, X.; Li, T.; Ren, J.; Hu, Q.; Liu, W.; J. Coord. Chem. 2014, 67, 2028.

26. Klapötke, T. M.; Chemistry of High Energy Materials; Walter de Gruyter: Berlin/New York, Germany/USA, 2011.

27. Li, F.; Bi, Y.; Zhao, W.; Zhang, T.; Zhou, Z.; Yang, L.; Inorg. Chem. 2015, 54, 2050.

28. Thottempudi, V.; Gao, H.; Shreeve, J. M.; J. Am. Chem. Soc. 2011, 133, 6464.

29. Kissinger, H. E.; Anal. Chem. 1957, 19, 1702.

30. Ozawa, T.; Bull. Chem. Soc. Jpn. 1965, 38, 1881.

31. Doyle, C.; J. Appl. Polym. Sci. 1961, 5, 285.

32. Cui, C.; Guo, X.; Geng, Y.; Dang, T.; Xie, G.; Chen, S.; Zhao, F.; Chem. Commun. 2015, 51, 9276.

Submitted: December 25, 2019

Published online: April 6, 2020 